\title{
Growing food, feeding change: towards a holistic and dynamic approach of eco-city planning
}

\author{
A.L. Vernay. T.B. Salcedo Rahola., W. Ravesteijn
}

\begin{abstract}
In response to increasing environmental problems and consciousness in relation to urbanization, more and more cities are trying to become eco-cities. We can question, however, whether these cities can be considered as sustainable cities. The eco-city concept usually includes criteria regarding energy and water consumption, transport, waste management, amount of green spaces, etc. However, food consumed in the cities is usually marginally taken into account. Moreover, implementation strategies necessary to successfully make a transition to sustainability are rarely mentioned. The goals of this paper are twofold. First, we will ask attention for urban agriculture and include food in the eco-city equation. Second, we will argue that eco-cities should not be considered as project but operated as a process.
\end{abstract}

\section{INTRODUCTION}

$\mathrm{M}$ ore than half of the world's population lives in urban areas concentrating and increasing the magnitude of social and environmental impacts. Increasing environmental concerns are putting additional pressure on municipalities which are expected to come up with strategies and measures to keep cities livable, minimize environmental degradation and prevent further contribution to global warming.

In response to these challenges an increasing number of initiatives aimed at sustainability have been and are being developed worldwide. In other words, more and more cities are trying to become eco-cities. We can question, however, whether these cities can be considered as sustainable cities. Sustainability is usually understood in a broad sense, encompassing both intergenerational and intragenerational solidarity in ecological as well as social terms. The Brundtland Report [1] defines sustainable development as "development that meets the needs of the present without compromising the ability of future generations to meet their own needs" (...). The report adds two concepts (needs, especially of the poor, and technological and organizational limitations) and, more importantly in this context, four interlinked strategies [2]:

1. Managing the impacts of populations on ecosystems

Manuscript received October 15, 2010

A.L. Vernay is with the faculty of technology Policy and management of Delft University of Technology, Delft, 2628BX Netherlands (phone: +31 (0)15 27 81653; fax: 303-555-5555; e-mail: a.b.h.vernay@ tudelft.nl).

T. B. Salcedo Rahola was with the faculty of technology Policy and management of Delft University of Technology. He is now with the OTB Research Institute for the Built Environment Delft, 2628BX Netherland (e-mail: T.B.SalcedoRahola@tudelft.nl).

W. Ravesteijn is with the faculty of technology Policy and management of Delft University of Technology, Delft, 2628BX Netherlands, (e-mail W.Ravesteijn@tudelft.nl).

978-1-4244-8479-9/10/\$26.00 (C2010 IEEE
2. Ensuring worldwide food security

3. Managing ecosystem resources

4. Creating sustainable economies

Ideally, eco-city planning should reflect all these strategies. In other words, an eco-city should be designed based on a broad perspective including an integrated, multi-purpose approach as well as "whole system design". However, current eco-city concepts, often focusing on a few aspects, generally miss the broadness this would require. Food production, for instance, is seldom mentioned in the eco-city discourse.

Moreover, the eco-city concept mainly focuses on technological solutions as if such a city could be designed on paper without including the complex social dynamics that take place in and outside the city. Following the argument put forward by Haughton (1999) that procedural equity is one of the key principles of sustainability [43], we believe that the process of implementation should be an integral part of the eco-city concept. Implementation strategies require "agents", usually a whole range of them, to take action. In our case this means that, apart from the urban planners and the city authorities, all relevant stakeholders should be involved in the design, planning, development and functioning of the city.

The goal of this paper is to explore the eco-city concept and strengthen it in two ways. First, we will include food in the eco-city equation. By doing so, we do not only aim to extend the eco-city concept, but we also seek to improve the efficiency of the material and energy cycles, thus both broadening and deepening the sustainability contents of the eco-city concept. Second, we will argue that eco-cities should not be considered as just a construction project but rather be planned, carried out and be operated as a process.

In the remaining parts of this paper, we will first give an historical overview of the eco-city concept. We will then explain and argue why food has its place in eco-city design. Consequently, using the Hammarby model as a starting point, we will show how food can be included in eco-city design and discuss the implications of doing so. Finally, we will consider implementation strategies and their contextual use.

\section{ECO-CITY}

An eco-city could be defined in many ways. We conceptualize it here as an urban environmental system in which input (of resources) and output (of waste) are minimized [3]. Though Richard Register's seminal work dates from 1987, eco-cities can be traced much further in time, depending on one's perspectives. In fact, in 1898, Ebenezer Howard with his concept of "garden city" was the first to provide an alternative to what was then mainstream urban planning [4]. One of the aspects of his idea was to 
design cities located in rural areas but with good connections to the urban centre and where citizens would live in harmony with their surrounding environment [4]. Garden cities really paved the way for a whole new line of thinking about cities. We can mention for example the neotechnic city of Geddes [6] in 1915, the biotechnic city of Mumford in 1938 [7] and the work of McHarg's on ecologically sensitive planning in the 70's [5, 8]. For a complete overview of historical perspective on eco-cities we refer to [5].

Since then a number of developments have been initiated worldwide. To name only a few, EVA Lanxmeer in the Netherlands in the mid 1990's, Hammarby Sjöstad in Sweden in the late 1990's, Masdar in Abhu Dabi in 2007, Tianjin in China in 2009 (for more examples, consult the eco-city survey completed by Joss, 2009 [42]). Each eco-city has its own set of technologies, governance arrangements, design criteria and requirements. These criteria generally include targets in terms of energy and water consumption, greenhouse gases emissions, water quality, type of material use, percentage of recycling, availability of public transport, amount of green spaces, urban density, amount of social housing, etc. However, food security, one of the sustainable development strategies supported by the Brundtland report, is very seldom considered or even mentioned in the design of eco-cities. Moreover, implementation strategies are usually left out or only dealt with very briefly.

\section{ECO-CITY AND FOOD}

Urban agriculture has a long history and still plays an important role in the developing and emerging countries. However, in the North, the connection between the urban and the rural areas has been weakened since a long time $[9,10]$ and among urban planners a tendency has emerged to consider food production as a strictly rural affair [11]. As such, food supply has been neglected in the planning of cities, which have become, by implication, more and more dependent on the global industrialised food system [12]. This is also true for eco-city planning where food production is a rather disregarded aspect. Most of the attempts to include food production in urban design have been based on the work on Bill Morrison and David Holgrem around the concept of permaculture, dating from the 1970s. Permaculture looks for the interactions between the landscape, the local ecosystem and the built environment and tries to foster an "ecological support web" [13] so that urban and ecosystem development reinforce and enhance each other. However, most existing examples are urban farms or relate to small scale urban development in low density areas and permaculture principles may be difficult to apply to dense areas.

However, the tides are turning and, after decades with little interest in it, food production starts to be seriously considered again in urban planning. For instance, in Beijing in order to help meeting the cities enormous and still rising demand for food, the municipality is planning to use about 3 million square meters of rooftop for growing fruits and vegetables over the next ten years [14]. There are a number of reasons why food should increasingly play a role in designing and governing (eco)-cities along with energy provision, water and waste management, employment, welfare, etc. The most often mentioned are food security [15], [16], health [17, 18], employment [10], sense of community [9, 10, 19] and sense of space [20], prevention of flood [21] and decrease of urban heat island [22]. Moreover, disregarding food production as an integral part of the urban condition, means ignoring the fact that food is closely related to energy production and consumption, need for transportation, water provision and consumption, recycling of waste, land use, etc [11]. In addition, we would like to argue that integrating food in the planning of eco-cities can also help in better closing the water, material and energy cycles. The notion of closing cycles, also referred to as systems integration, is promoted by scholars in the fields of industrial ecology and 'cradle to cradle' as one of the answers to current environmental challenges.

IV. INTEGRATING FOOD IN ECO-CITY DESIGN: THE HAMMARBY MODEL AS A CASE STUDY

\section{A. The Hammarby model: an introduction}

Hammarby Sjöstad is a district in Stockholm, Sweden, that started to be developed in the late 1990's. The municipality had high ambitions for this district which should become a show case for urban sustainability. One of the main ideas in its design was to copy natural processes and as such to close the material, water and energy cycles as much as possible[23]. Developed together with the local infrastructure companies this vision gave rise to what is now known as the eco-cycle or Hammarby model (see figure 1).

In brief, all buildings in the Hammarby model are connected to a district heating network. One of the main sources of energy in this network comes from domestic waste from which energy is recovered in a cogeneration plant. Moreover, the purified wastewater represents another source of energy. Indeed, after the treatment processes, it still contains heat that can be extracted and upgraded using a heat pump and fed into the district heating network. The remaining cold water can then be used for cooling purposes in commercial and office areas. In addition, sludge resulting from the wastewater treatment process is digested in order to produce biogas that once upgraded can be used for transport and cooking purposes. We would like to stress that, here, we take the Hammarby model out of its context and use it as a theoretical tool. Consequently, our suggestions are not developed for Hammarby specifically but are meant to illustrate how food can be included in such an integrated model and what the advantages are of doing so. Figure 2 shows a diagrammatic representation of the Hammarby Model.

In fact, a number of reasons support our decision to use this model as a starting point. To begin with, this model is not only theoretical but has actually been implemented and is the result of a well thought and well planned design process. 
Furthermore, the model is also very appropriate as a theoretical tool to brainstorm about how systems integration can be implemented in urban design. In fact, it is inspiring a number of municipalities and provinces worldwide in their quest for urban sustainability through systems integration [24]. Finally, the Hammarby model takes a holistic perspective by seeking to integrate the systems of energy, water, waste and transport. Nevertheless, connections to the

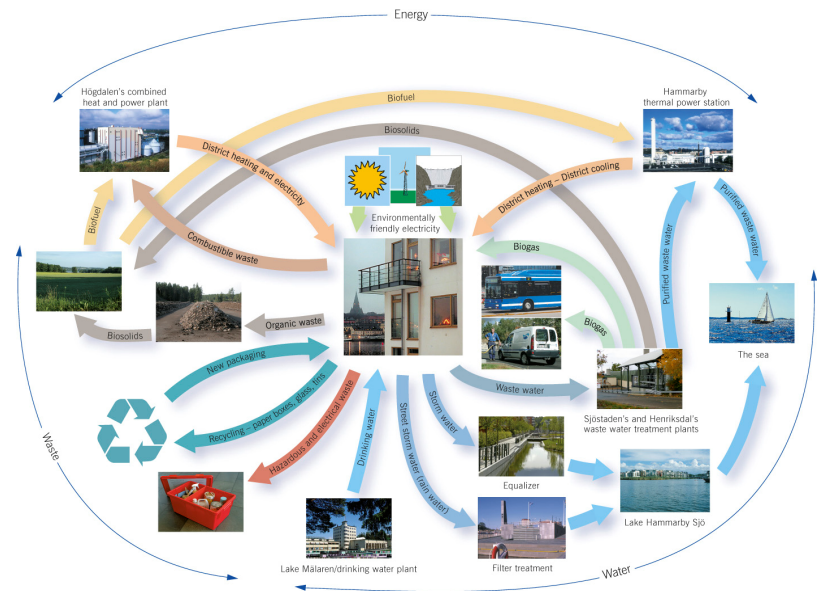

Fig.1. The Hammarby or eco-cycle model [24]

food system are very limited in the model and, consequently, it is a good base for pointing out how food could be included in such an integrated design.

\section{B. Integrating food in the Hammarby Model}

As previously stated, food is marginally present in the Hammarby model. The only elements are the fields that appear as the end destination for organic waste. In other words, the cycle involved is not closed. Decontextualizing the Hammarby model, we have included three new food-related elements: greenhouses, building farms and green roofs (see figure 3). In fact, land use in cities is already highly stressed by different kind of uses; dwellings, offices, industry, transport, energy and water infrastructure. Therefore, due to competition on land use, food production is only possible in the form of intensive agriculture and/or at the individual level. By including these three elements the food loop has been closed. Moreover, intensive agriculture enabled new interactions with the energy and water systems, thus improving both cycles (see figure 3 ).

Let us discuss in somewhat more detail the three foods related elements that have been added to the model and the interactions that they make possible:

- Green Roofs will only cover a small percentage of food needs. Nevertheless, they offer the possibility to involve citizens and connect them to natural cycles [25]. Moreover, green roofs enormously improve building's insulation, offer protection for the city drainage in case of rainstorm through water buffering and they clean the air. It is a complete solution for city problems [26]. On the other hand, green roofs are difficult to apply on pitched roofs and they compete with solar panels.
- Greenhouses offer the possibility to grow a large range of crop, with a considerably higher production than common agriculture [27]. The production period can be enlarged and the efficiency of the land improved with extra light hours or

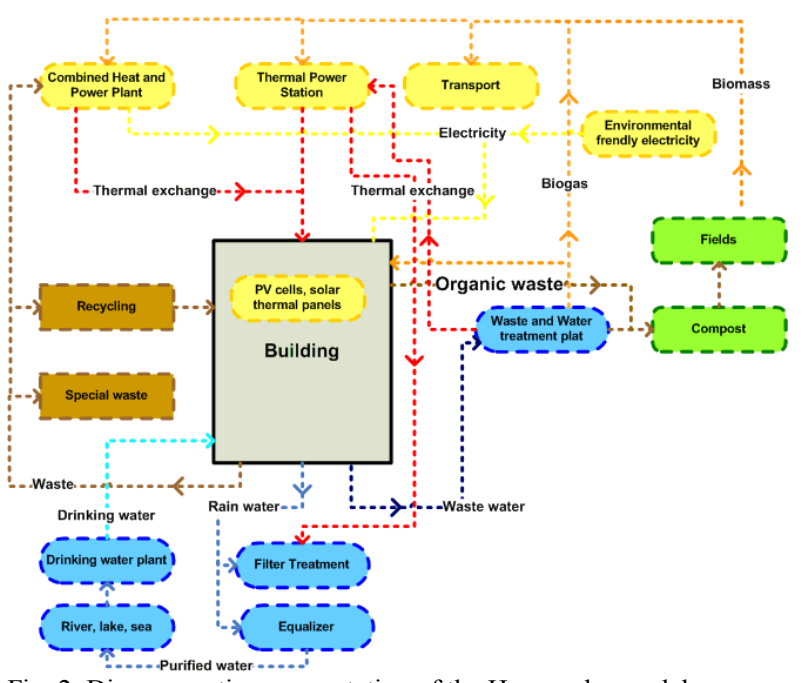

Fig. 2. Diagrammatic representation of the Hammarby model

extra $\mathrm{CO}_{2}$. Dutch and Spanish greenhouse products are competing with the United States market with local production [28]. However, greenhouses have considerable higher economic and energetic cost and are nowadays only profitable in certain countries for vegetables and fruits, not for

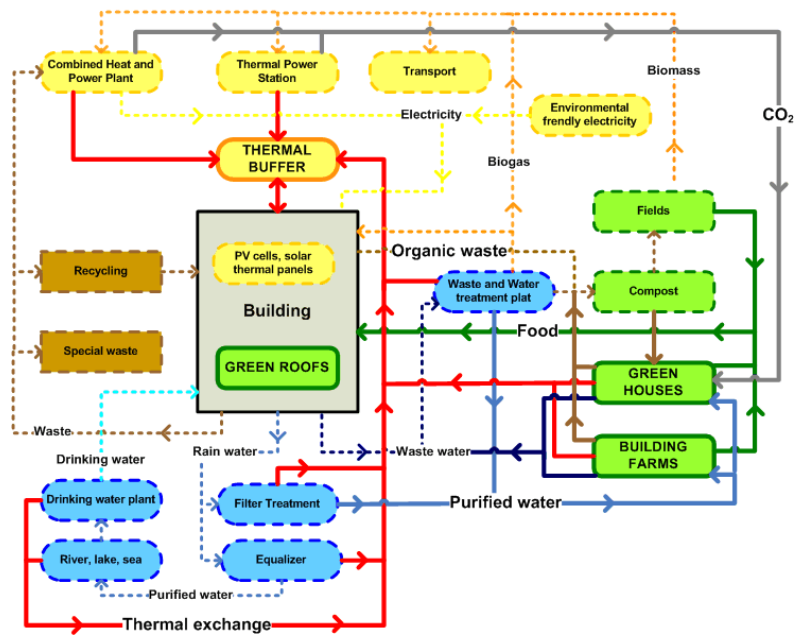

Fig.3. Introducing food in the Hammarby model

extensive crops as corn, wheat or rice.

- Building farms offer the possibility to increase the density of meat and fish production, lowering land use requirements and allowing interconnections with the energy, water and waste loops. This concept has been theoretically developed quite extensively by the pig towers designed by Winy Mass [29] in the Netherlands; and has been implemented in singular cases, for example a shrimp farm in Rotterdam harbor [30].

The three new food-producing elements introduced in the Hammarby model provide several new interactions with other already existing elements. First, greenhouses and building 
farms can use recycled water: filtered rainwater and treated wastewater. The use of recycled water is already a common practice in regions with water shortage for irrigation of golf courts for instance [31] and it has been demonstrated to be successful. Nevertheless, appropriate soil management is needed to mitigate the negative impacts of sodium and salt accumulation [31]. Second, greenhouses and building farms produce wastewater and organic waste that can be used as compost for the same greenhouses and as input for the production of biogas in the wastewater treatment plant. The amount of biogas available increases enormously compared to the Hammarby case. In fact in projects as Zonneterp, in the Netherlands, it is calculated that a greenhouse could be the energy source for a certain number of dwellings [32]. Third, part of the $\mathrm{CO} 2$ produced in the power plants could be used in the greenhouses as is already done in the Netherlands. And finally, greenhouses are big solar collectors and building farms are big heat sources. It is especially interesting to add all these new thermal elements to the already existing thermal elements of the city connected in a thermal network that can supply heat and cold. Consequently, however, it is necessary to have a thermal buffer that could match supply and demand. This could be done with the use of underground thermal reservoirs combined with heat pumps (see [33] for such an example).

In total, four new elements and six new interactions have been included in the city design and in the Hammarby model. We will discuss the efficiency gains this offers as well as the newly emerging central role of the waste water treatment plant in the whole urban eco-system below.

\section{Discussion}

Food and systems integration: First of all, in our upgraded model, we have introduced three new components directly related to food production: green roofs, building farm and greenhouses. These three elements have made (even more) relevant the need for a fourth component, the thermal buffer, to improve the energy loops. Moreover, these new components allowed the creation of six new interactions. These interactions do not only concern food and food waste but also energy and water exchanges. Our example thus shows that including food in eco-city design makes systems integration more complete and allows more efficient use of water and energy resources.

Second, we can see that in our upgraded model, the waste water treatment plant plays a really central role in closing the cycles by recovering energy and material. Traditionally, waste water treatment plant consumes energy to purify sewage water. More and more frequently, the sludge that they produce is used to generate biogas, recovering part of the energy used. Moreover, in some cases the heat contained in the purified water is used as a heat source for district heating purposes. In our model, we do not only take advantage of these technological solutions, but we also use the purified waste water as a source for irrigating greenhouses.

Limitations of our approach: By reflecting on the upgraded model that we have presented, a number of limitations can be mentioned. First, among the technological solutions presented in our upgraded model some compete with each other. For example, green roofs are only partially compatible with PV and solar collectors. Therefore, a decision needs to be taken regarding what is the most optimal situation in each case based on the local needs, interests and circumstances. Similarly, technological options have been suggested assuming their compatibility with existing institutional arrangements (e.g. the reuse of treated wastewater for irrigation purposes). This may, however, not always be the case, impeding the implementation of certain solutions. In fact, when designing an eco-city, one has to consider the geographical character of the area, resource availability, technological possibilities, social demand and values as well as institutions. It results in complex optimizing issues and stresses the need to think strategically about which mix of technological solutions is appropriate given the specific local conditions. This also implies that the upgraded model presented in this paper should not be understood as a description of what an eco-city design should look like. Instead it should be used as a source of inspiration for thinking about possibilities to optimize resource use in the design of an eco-city.

Second, the suggested solutions to include food in eco-city planning have been limited to those that can be implemented in the city-scape. Solutions or interactions taking the surroundings of the city into account are thus outside of the scope of this paper. However, we recognize that it is also necessary for cities to deepen their interactions with the rural areas and regain influence on the rural processes that play such a vital role in food production. This is important particularly when considering that only a limited percentage of the total demand of food can be produced within the geographical limits of the city [18].

Third, the Hammarby model was designed for an urban development in a highly developed country, Sweden. As such, we may be criticized for having a western bias and we would like to mention that we acknowledge that this model is not applicable everywhere and that it would be difficult to implement in some developing countries for instance. However, we think that our upgraded model is at least suitable for implementation (requiring adaptation to local conditions) in emerging economies where resources are available to implement these technological solutions (or at least some of them). In these countries, as in most developing countries, food production plays a major role from a socio-economic perspective, while many city inhabitants are (still) involved in or connected to agriculture. In as far as our suggestions require the latest technologies available, it has to be emphasized that emerging countries are the right place for 'leapfrogging', as they are entangled in dynamic development processes not showing some of the lock-in that hamper some of the developed countries.

Fourth, the model presented here is purely conceptual and a mass flow analysis would be required to quantitatively validate our argument regarding the increased environmental performance inherent in our approach. 


\section{IMPLEMENTATION STRATEGIES}

Thus far, our discussion mainly focused on technological possibilities. It is obvious however, that eco-cities have to be planned and built, but how this should be done is not described and analyzed very well in the literature. In fact eco-cities are usually presented by showing ${ }^{1}$ their masterplan (e.g. Masdar [34]); ${ }^{2}$ the key performance indicators that they use (e.g. Tianjin [35]); ${ }^{3}$ and/or the technological model that they follow (e.g. Hammarby [36]). However, the process that should lead to the completion of these eco-cities is rarely mentioned. In this section we argue that the process itself is essential. Implementation should be studied in more depth and not be considered as complementary to the eco-city concept; it is instead an integral part of it.

\section{A. Project versus process management}

Some compelling arguments can be given why eco-cities should not be considered projects but dynamic processes [37]. First of all, the long-term character of the effort: eco-city planning ideally leads to a sustainable city in the long term (up to several decades in the future). Insights in what sustainable means change over time and new strategies will be developed to make a city more (effectively) sustainable, as is shown in this paper by adding food to the 'city system'. Next to that, an eco-city is not finished overnight and while under construction the circumstances inside and outside the city change. Additionally, once finished, the eco-city could possibly not be used as the designers intended to because of numerous reasons which should lead to adaptation of the (built) city plans.

Considering these arguments and the arguments above for a city being a complex system, eco-city planning has to be considered in terms of a transition. We will briefly discuss transition theory and, consequently, apply it eco-city planning.

\section{B. Transition contexts and intervention tools}

In brief, transitions are processes in which niche innovations resulting from landscape pressures develop into new mainstream regimes, replacing older regimes [38]. There is not a single type of transition. In fact, transitions may follow different pathways, depending on the context in which they are taking place $[39,44]$. Regime change takes place in response to selection pressures and the way these are defined or articulated by key actors. Actors may or may not coordinate their response to selection pressure. Moreover, resources used to respond to these pressures may originate from the "establishment" (or existing regime) or come from external sources. As a consequence, four types of transition context can be distinguished (see figure 4): endogenous renewal, reorientation of strategies, purposive transition and emergent transformation.

Examples of contextually conditioned transition pathways, all in the domain of energy, are:

- Endogenous renewal: capture and storage of CO2

- Reorientation of trajectories: installation and use of small scale Combined Heat and Power generation in the horticulture sector in the Netherlands
- Purposive transition: transformation of Dutch households and industries to a gas fired heating system

- Emergent transformation: the world-wide (partial) replacement of oil by gas.

Eco-city planning assumes the form of different pathways in different countries, dependent on the position of the initiators

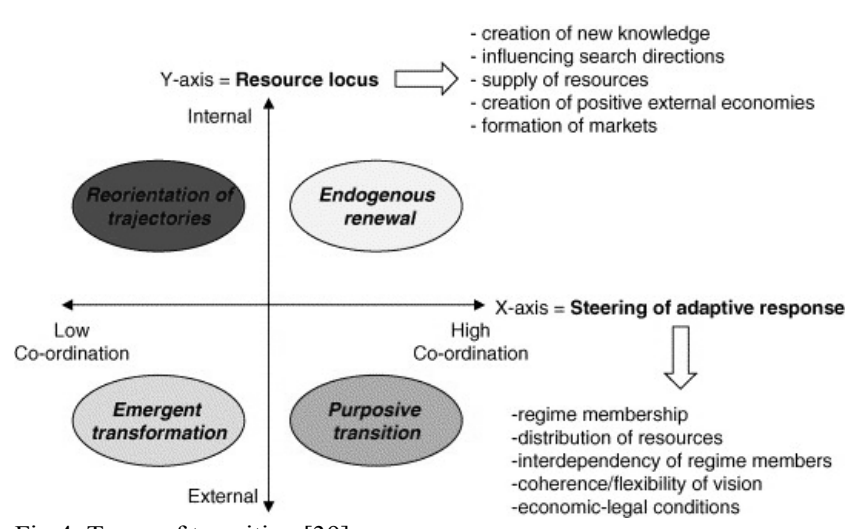

Fig.4. Types of transition [39]

and the locus of the resources. E.g. top-down political decision-making seems to be essential in some Asian countries, while bottom-up initiatives, either dominant regime-based (urban planners) or from the outside (citizens) seem the characteristic for some Western countries. However, city-planning everywhere involves a variety of stakeholders, including authorities, citizens, companies and knowledge institutes, and this has to be considered in any pathway to be followed.

Transition processes require implementation strategies, ranging from command-and-control to networking [39]. The most appropriate strategy for eco-cities seems to be backcasting, as it accounts for the long-term and dynamic character of eco-city planning as well as the multitude of actors involved.

\section{Eco-city process management}

Backcasting is a method for bringing about long-term processes of change and transformation through vision building as a basis for short-term actions, taking not only current developments, trends and stakeholders into account but their dynamics over time as well [40]. In our case, this means constituting a long term sustainable city vision, which consequently determines the direction for short-term planning and construction activities. Crucial in this method, emphasizing that the design of a future sustainable city could be nothing more than a vision guiding the way for today's city planning, is the involvement of all stakeholders.

\section{How could our model be implemented in practice?}

The Hammarby case can be referred to once more. There it was the municipality that took the initiative and convinced all companies involved to work together and define a common vision as a base of operation. This appeared to be a decisive factor in the implementation [41]. However, this is but one strategy and more research is needed to analyze and compare different governance models in order to be able to give more precise recommendations. 


\section{CONCLUSION}

Eco-city planning is all the rage now throughout the world and this justifies what has been done in this paper: a reflection of the phenomenon from a critically-constructive point of view. We have explored the concept of eco-city and have proposed to improve it substantially from a sustainability perspective. First, the concept has been broadened by including food production, in this way also making the water and energy cycles more efficient. Second, the concept has been made more dynamic, by considering eco-city planning as a process. Backcasting was put forward and discussed as an appropriate implementation strategy. Eco-city planning is a promising development in view of urbanization and environmental problems. In order to prevent it from being just a hype, it is necessary to give it strong scientific underpinnings. We hope this paper has made a contribution to this mission.

\section{ACKNOWLEDGMENT}

The authors thank Gertjan de Werk for his constructive input.

\section{REFERENCES}

[1]. Brundtland, G.H., Our common future. 1987, Brussels: World Commission on Environment and Development.

[2]. Shrivastava, P., The role of corporations in achieving ecological sustainability. The Academy of Management Review, 1995. 20(4): p. 936-960.

[3]. Register, R., Ecocity Berkeley: building cities for a healthy future. 1987, North Atlantic Books.

[4]. Howard, E., Garden Cities of Tomorrow. 1902, London: Faber and Faber.

[5]. Basiago, A.D., The search for the sustainable city in 20th century urban planning. The Environmentalist, 1996. 16: p. 135-155.

[6]. Geddes, P., Cities in evolution. 1948 ed. 1915, London: Williams and Norgate.

[7]. Mumford, L., The Culture of Cities. 1938, New York: Harcourt brace Jovanovich.

[8]. Canfield, C., Cerro Gordo: exploring symbiotic community. Cerro Gordo Town Forum, 1994. 20: p. 15-17.

[9]. Gündel, S., A synthesis of urban and peri-urban agricultural research commissioned by the RNRRS Programme. 2006: Edinburgh.

[10]. Sonnino, R., Feeding the City: Towards a New Research and Planning Agenda. International Planning Studies, 2009. 14(4): p. 425-435.

[11]. Morgan, K., Feeding the City: The Challenge of Urban Food Planning. International Planning Studies, 2009. 14(4): p. 341-348.

[12]. B. Donald and A. Blay-Palmer, The urban creative-food economy: Producing food for the urban elite or social inclusion opportunity? Environment and Planning, 2006. 38(10): p. 1910-1920.

[13]. Roley, B., The Future of Housing. In Urban Ecology. 1991: Eco-Cities 1991.

[14]. Halweil, B. and D. Nierenberg, Farming the city, in State of the world Our Urban Future, The Worldwatch Institute, Editor. 2007, The Worldwatch Institute.

[15]. Morgan, K. and R. Sonnino, The urban foodscape: World cities and the new food equation. Cambridge Journal of Regions, Economy and Society, 2010: p. 1-16.

[16]. Reynolds, B., Feeding a World City: The London Food Strategy. International Planning Studies, 2009. 14(4): p. 417-424.

[17]. Wrigley, N., 'Food Deserts' in British cities: Policy context and research priorities. Urban studies, 2002. 39(11): p. 2029-2040.

[18]. Guy, C., G. Clarke, and H. Eyre, Food retail change and the growth of food deserts: A case study of Cardiff. International Journal of Retail and Distribution Management, 2004. 32(2): p. 72-88.

[19]. Waggoner, P.E., How can EcoCity get its food? Technology in Society, 2006. 28: p. 183-193.
[20]. Martin, R. and T. Marsden, Food for urban spaces: The development of urban food production in England and Wales. International Planning Studies, 1999. 4(3): p. 389-412.

[21]. Girardet, H., The Gaia Atlas of Cities. New directions for sustainable urban living. 1996, London: Gaia Book Limited.

[22]. Hawkins, T.W. and et al, The Role of Rural Variability in Urban Heat Island Determination for Phoenix, Arizona. Journal of Applied Meteorology, 2004. 43: p. 476-486.

[23]. Hammarby Sjöstad. Hammarby Sjöstad - a unique environmental project in Stockholm. 2007 [cited: Available from: http://www.hammarbysjostad.se/]

[24]. SWECO - Sustainable Engineering and Design. Sustainable city development. 2010 [cited 30 Novembre 2009].

[25]. Greenspace, Final report. 2005.

[26]. Oberndorfer, E. and e. al, Green Roofs as Urban Ecosystems: Ecological Structures, Functions, and Services. BioScience, 2007. 57(10): p. 823-833.

[27]. Papadopoulos, A.P. and D.A. Demers, Greenhouse Horticulture Encyclopedia of Food \& Culture, ed. S.H. Katz. Vol. 2. 2003: Gale Cengage. [28]. Cantliffe, D.J. and J.J. Vansickle, Competitiveness of the Spanish and Dutch Greenhouse Industries With the Florida Fresh Vegetable Industry, University of Florida Institute of Food and Agricultural Sciences, Editor. 2009: Gainesville.

29]. Maas, W. Long term is not the same as sustainable. in Holcim forum for sustainable construction. 2004. Zurich: Holcim Foundation for Sustainable Construction.

[30]. Baas, L., Industrial symbiosis in the Rotterdam Harbour and Industry Complex: reflections on the interconnection of the techno-sphere with the social system. Business Strategy and the Environment 2008. 17(5): p. 330-340.

[31]. Qian, Y.L. and B. Mechamb, Long-Term Effects of Recycled Wastewater Irrigation on Soil Chemical Properties on Golf Course Fairways. Agron 2005. 97: p. 717-721.

[32]. Wortmann, E.J.S.A. and e. al, De Zonneterp -een grootschalig zonproject. 2005, Innovatie Netwerk Groene Ruimte en Agrocluster Utrecht.

[33]. T. Schmidt and H. Müller-Steinhagen. The central solar heating plant with aquifer thermal energy store in rostock - results after four years of operation. in 5th ISES Europe Solar Conference. 2004. Freiburg, Germany.

[34]. Masdar city. Master plan. 2009 [cited May 2010; Available from: http://www.masdarcity.ae/en/index.aspx].

[35]. Singapore Government. Key Performance Indicators of the Eco-city 2010 [cited May 2010]; Available from: http://www.tianjinecocity.gov.sg/. [36]. Stockholm Municipality, Hammarby Sjöstad - a unique environmental project in Stockholm. 2007, Alfaprint.

[37]. Bruin, H.d. and E.t. Heuvelhof, Management in networks. 2008, London and New York: Routledge.

[38]. Geels, F.W., Technological transitions as evolutionary reconfiguration processes: a multi-level perspective and a case-study. research Policy, 2002. 31(8/9): p. 1257-1274.

[39]. Smith, A., A. Stirling, and F. Berkhout, The governance of sustainable socio-technical transitions. Research Policy, 2005. 34(10): p. 1491-1510.

[40]. Quist, J., Backcasting for a sustainable future: the impact after 10 years, in Technology Dynamics \& Sustainable Development Group. 2007, Delft University of Technology: Delft.

[41]. Vernay, A.L., et al. Closing the loop at the local level: technological or socio-economic challenges? The case of Hammarby Sjöstad, Stockholm in Summer Symposium on Sustainable Systems (4S) upcoming. Sannäs.

[42]. Joss, S., Eco-cities - a global survey 2009. WIT Transactions on Ecology and the Environment, 2009.129, p. 239-250.

[43] Haughton, G., Environmental Justice and the Sustainable City. Journal of Planning Education and Research, 1999, 18(3), p. 233-243 